${ }^{3}$ Gruneberg, H., The Genetics of the Mouse (Martinus Nijhoff, The Hague, 1952).

${ }^{4}$ Kirkman, H., and Algard, F. T., The Golden Hamster (edit. by Hoffman, R. A., Robinson, P. F., and Magathas, H.) (Iowa State University Press, Ames, 1968).

\section{Phloem Physiology and Protective Sealing Mechanisms}

Recently Dr Spanner, in a review "Transport in the Phloem"1, described certain aspects of my work ${ }^{2}$ but reinterpreted my reported observations in accordance with his scheme to explain the mechanism of phloem transport. His description that the massage pretreatment applied to Ricinus stems in my experiments was "gentle" is not correct. The theory behind the method is to compress phloem sieve tubes containing sap under pressure of about $10 \mathrm{bar}$, so as to make it surge rapidly along the tubes; manual pressure was applied firmly though not so as to produce detectable damage during the application. Similarly the brief application of quite strong pressure is needed to stop exudation completely.

He describes as "contrived" my proposals for the sieve plates as control systems, governed by sealing and anti-sealing mechanisms, in view of the "obvious" alternative that the pretreatment merely disrupts the natural system. Yet callose deposition, one accepted sieveplate sealing mechanism, is known to be reversible ${ }^{3}$. Further evidence supporting my theory will be published shortly in which illustrations of the complexity of the sealing system are presented. For example, a cut may exude, then stop completely for a time, begin again without interference and finally cease (the "re-bleed phenomenon"), which defies a simple explanation.

A further important finding is that Ricinus plants may exude considerable amounts of sap without pretreatment if they are grown sufficiently vigorously ${ }^{5}$. Such exudation can also be stopped by the temporary application of pressure. More than $3 \mathrm{ml}$. of phloem exudate has been collected from a single $5 \mathrm{~mm}$ cut in an unmassaged plant about $50 \mathrm{~cm}$ tall (Baker and Hall, unpublished result), whereas the corresponding maximum on record from a single cut in a vigorous massaged plant is now more than $10 \mathrm{ml}$. This rapid collection of phloem sap from plants in amounts too large to be accounted for by turgor release from single cells is a most serious obstacle to acceptance of an "occluded pore" mechanism. Not only is massage pretreatment inessential, but the amounts collected above and below cuts are in roughly equal amounts as one might expect of a simple pressure release. We should expect the output from a pumping system between leaves and roots to be polarized and produce dissimilar amounts.

It is surprising that the palm sugar industry, which produces thousands of tons of sugar annually from phloem exudate ${ }^{6}$, has been so ignored by plant physiologists. It was from Bose's account ${ }^{7}$ of the collection system that my successful massage pretreatment was devised. There are local variations in technique but my enquiries into these have been curtailed by the Pakistan troubles. But an eyewitness, Mr Syed Hadiuzzaman of Dacca University, has described a method for the collection of Phoenix phloem sap without massage pretreatment, by "V" shaped incisions alone. Experts incise the upper trunks after removal of a series of leaf bases, which otherise protect the tissues from injury. Cuts are renewed every few days and provide several litres of sap (about $14 \%$ sucrose) per day. Thus it seems that the mechanisms involved are similar in Phoenix and Ricinus and pretreatment by "disruptive" massage is not essential for exudation from either.

In terms of evolutionary development it can be argued ${ }^{3,4}$ that such a rich potential food supply as phloem has become adapted to seal rapidly to withstand the onslaught of predators. Probably this has been largely achieved. Exceptions are small insects, for example aphids, which probably tap the sieve tubes at rates too slow to trigger the sealing response ${ }^{3}$, and larger animals, for example the sapsucker, a bird which makes a succession of wounds so bypassing blocked tissues ${ }^{8}$. If man can succeed where most animais would fail, large resources of sugars, amino-acids and proteins should become available "on tap" from otherwise useless vegetation.

A serious problem in studying phloem physiology has been the difficulty of establishing if tissue is still capable of conduction after being treated experimentally. The sensitivity of the tissue to manipulation is now beyond question. If sieve plates have become adapted to seal rapidly, this probably explains why considerable efforts, using largely empirical techniques, to demonstrate "open" sieve plate pores have produced inconclusive or controversial results.

If the explanation proposed is correct the most efficient way to prove the mechanism of phloem transport is to elucidate further the physiology of the sealing mechanisms with a view to controlling them. We now have plants in which the system can be studied systematically (Yucca ${ }^{9}$, Phoenix, and Ricinus) and only when the sealing mechanisms are fully understood will it be possible to demonstrate convincingly the ultrastructure of sieve plate pores in the natural state.

\section{JoHn A. MILbURN}

Department of Botany,

The University,

Glasgow $W 2$

Received August 18, 1971.

DR SPANNeR writes: I am grateful to Dr Milburn for correcting the wrong impression given by my use of "gently". Further thought on his interesting results inclines me to greater sympathy with his view. My reaction had been to conclude that his metabolic sealing-antisealing mechanism had involved P-protein, a conclusion against which strong arguments have been raised ${ }^{1}$. If he is thinking rather of callose formation I find his suggestions plausible. But in that case they seem to me to lose their relevance to the controversy about whether the sieve plate pores are normally occupied by $\mathbf{P}$-protein, as my Fig. 1 indicated $^{10}$. One only has to assume that the usual brevity of exudation hinges on the formation of callose rather than on the filling of the pores with P-protein to see this. For I believe that the electro-osmotically significant P-protein in the pores does not require very much force to displace it. (I am not thinking, of course, of massive protein plugs in the lumen.) Consequently the situation at the cut surface is dominated by the huge turgor gradient, and pays little attention to whether the pores are normally open or occluded. That exudation from the two surfaces of the cut should be more or less equal (not always found incidentally ${ }^{11}$ ) is understandable. Similarly the re-bleed phenomenon does not seem so hard to explain; pressure build-up might dislodge a proteinaceous accumulation at a callose-constricted sieve plate.

\section{C. Spanner}

Bedford College,

University of London,

Regent's Park,

London NW1 4 NS

Received September 5, 1971.

${ }^{1}$ Spanner, D. C., Nature, 232, 157 (1971).

2 Milburn, J. A., Planta, 95, 272 (1970).

3 Zimmermann, M., in Physiology of Plant Growth and Development (edit. by Wilkins, M. B.), 383 (McGraw-Hill, London and New York, 1969).

${ }^{4}$ Milburn, J. A., Planta, 100, 143 (1971).

5 Hall, S. M., Baker, D. A., and Milburn, J. A., Planta, 100, 200 (1971).

${ }^{6}$ Schery, R. W., Plants for Man, 346 (Allen and Unwin, London, 1954).

7 Bose, J. C., Plants and their Autographs, 154 (Longmans, Green and Co., London, 1947).

${ }^{8}$ Crafts, A.'S., Translocation in Plants, 97 (Holt, Rinehart and Winston, New York, 1961).

9 Tammes, P. M. L., and Die, J. van, Acta Bot. Neerl., 13, 76 (1964).

10 Spanner, D. C., Nature, 232, 157 (1971).

11 Eschrich, W., Planta, 60, 216 (1963). 